\title{
BENDING RADIOGRAPHS AS A PREDICTIVE FACTOR IN SURGICAL CORRECTION OF ADOLESCENT IDIOPATHIC SCOLIOSIS
}

Alberto Ofenhejm Gotfryd ${ }^{1}$, Fernando José Franzin ${ }^{2}$, Patrícia Rios Poletto ${ }^{3}$, Alexandre Spertini de Laura ${ }^{4}$, Luis Carlos Ferreira da Silva

\section{ABSTRACT}

Objective: To evaluate the use of x-rays in dorsal decubitus, as a predictive factor for surgical correction of the main thoracic curve using pedicle screws, on patients with idiopathic adolescent scoliosis. Method: Twenty patients with idiopathic adolescent scoliosis of Lenke types $1 \mathrm{~A}$ and $1 \mathrm{~B}$ who were operated using a technique only involving pedicle screws by means of the posterior route were evaluated clinically and radiographically. The curve flexibility was calculated by means of active supine lateral oblique radiographs. The postoperative values for the main thoracic curve were included in a mathematical equation proposed by Cheung et al., with the aim of predicting the expected angular result from the surgical correction. The difference between the expected and actual postoperative results was then investigated regarding its statistical significance. Results: There was statistical significance for all the cases studied, between the values predicted before the operation and the radiographic findings immediately after the operation $(p<0.005)$. Conclusions: It is possible to predict the percentage surgical correction of the main thoracic curve that will be achieved using pedicle screws in patients with idiopathic adolescent scoliosis of Lenke types $1 \mathrm{~A}$ and $1 \mathrm{~B}$, by means of preoperative supine oblique radiographs.

Keywords - Scoliosis; Arthodesis; Adolescent; Radiography, Bone Screw

\section{INTRODUCTION}

Adolescent idiopathic scoliosis (AIS) is a threedimensional deformity of the spine. Curvature with angular values greater than 40 degrees, as measured using Cobb's method ${ }^{(1)}$, is generally an indication for surgical treatment in skeletally immature individuals ${ }^{(2,3)}$.

Preoperative determination of curve flexibility is a fundamental stage in the surgical planning, since it guides the selection of levels that are to be fused ${ }^{(2)}$. Furthermore, radiographic evaluation may suggest

a need to carry out additional procedures, such as osteotomy, anterior release or use of a greater number of implants ${ }^{(4-6)}$.

Several radiographic methods for determining the flexibility of scoliotic curves have been described, such as use of active lateral oblique views ${ }^{(7-10)}$, views under traction in dorsal decubitus ${ }^{(6,11)}$ and views with a fulcrum at the apex of the deformity in lateral decubitus ${ }^{(4,12)}$, among others. In our service, we use radiographs with an active lateral oblique view in dorsal decubitus, since this is easy to perform and inexpensive.

\footnotetext{
1 - MSc. Head Physician of the Spine Group, Department of Orthopedics and Traumatology, Santa Casa da Misericórdia de Santos, Santos, SP, Brazil.

2 - Specialist Physician in the Spine Group, Department of Orthopedics and Traumatology, Santa Casa da Misericórdia de Santos, Santos, SP, Brazil.

3 - PhD. Professor in the Physiotherapy Course, Federal University of São Paulo, São Paulo, SP, Brazil.

4 - Third-year Resident Physician in the Department of Orthopedics and Traumatology, Santa Casa da Misericórdia de Santos, Santos, SP, Brazil.

Work performed in the Department of Orthopedics and Traumatology, Santa Casa da Misericórdia de Santos.

Correspondence: Av. Ana Costa 259/51, Encruzilhada, 11060-001 Santos, SP. E-mail: albertocoluna@yahoo.com.br
}

Work received for publication: December 21, 2010; accepted for publication: March 25, 2011.

The authors declare that there was no conflict of interest in conducting this work 
Although some authors ${ }^{(4,12)}$ have previously described use of radiographic views with a fulcrum in operative planning for patients with AIS, no data are available on the effectiveness of radiographs with lateral oblique views, among patients operated exclusively using pedicle screws.

\section{OBJECTIVE}

To evaluate the use of radiographs with the lateral oblique view in dorsal decubitus as a predictive factor for surgical correction of the main thoracic curvature in patients with AIS, solely using pedicle screws.

\section{METHODS}

The medical files of 20 patients with AIS who were treated surgically between July 2007 and July 2010 were retrospectively reviewed. All the operations were performed by the same team (senior surgeon and auxiliary), using the same material and technique. All the patients came from the spine outpatient clinic of the Department of Orthopedics and Traumatology, Santa Casa da Misericórdia de Santos.

The following were considered to be inclusion criteria: individuals of both sexes; with AIS; diagnosed and operated between the ages of 11 and 17 years; presentation of scoliotic deformity of more than 40 degrees, as measured using Cobb's method ${ }^{(1)}$; classified by Lenke et $a l^{(7)}$ as type $1 \mathrm{~A}$ or $1 \mathrm{~B}$; treated with selective arthrodesis of the thoracic curve by means of a posterior access, with an upper anatomical limit for fusion at T4 and a lower limit at L1; and use of pedicle screws alone in the assemblies. Among the 20 patients included in this study, 17 (85\%) were female and three (15\%) were male; $45 \%$ presented Risser's sign, which was classified as type 4 at the time of the surgery. The patients' mean age was 14.1 years, and $70 \%$ of the patients presented a curve classified as Lenke $1 \mathrm{~A}$ and $30 \%$, as Lenke $1 \mathrm{~B}$.

Patients who presented scoliosis secondary to any other cause, patients whose operations involved implants other than solely pedicle screws and cases in which the arthrodesis involved vertebrae above T4 or below L1 were excluded. The operative technique for insertion of the pedicle screws was "freehand", based on anatomical markers. Only monoaxial pedicle screws (with a fixed head) were used, and the curves were reduced by means of the maneuver of derotation of the nail at the concavity. A second nail (positioned at the convexity of the curve) was fixed in situ. All the implants used were of the same brand and model (Universal Spinal System 1, Synthes), and were made of titanium. The patients underwent operations consisting of an adaptation of the technique described by Cotrel and Dubousset ${ }^{(13)}$. In this, 10 pedicle screws were positioned in vertebrae that were considered to be strategic: four at the base, three in the central vertebrae (or "heart" of the curvature) and three at the top.

The patients were documented by means of panoramic radiographs while they were standing upright, in the anteroposterior (AP) and lateral (L) views, before the operation and during the immediate postoperative period (Figure 1).

Radiographs in lateral oblique view were produced in accordance with the description by Moe and Byrd $^{(2)}$, with the patient positioned in dorsal decubitus and promoting the greatest possible active lateral flexion of the spine (Figure 2). This examination was monitored by a physician and was documented in two films: one to measure the main thoracic curve and the other to measure the proximal and lumbar thoracic curve (Figure 3).

The next step was to determine the pre and postoperative Cobb angles of the main thoracic curve and its lateral inclinations. The main thoracic curve values before and after the operation were used to obtain the flexibility rate of the curves (which was indicative of the possibility of curve correction based on

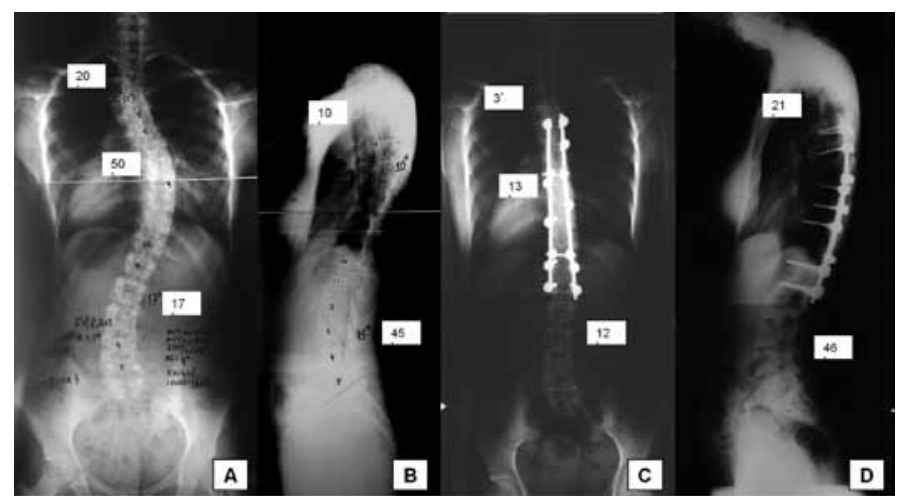

Figure 1 - Representative radiographic images of the study sample. A) Preoperative AP radiograph. B) Preoperative lateral radiograph. C) Immediate postoperative AP radiograph. D) Immediate postoperative lateral radiograph. 
radiographs in lateral oblique view) and the surgical correction rate of the curves (which was indicative of the real correction of the curve that was obtained through the surgical treatment), in accordance with the equations proposed by Cheung et al ${ }^{(4)}$ (Figure 4).

The equation for predicting the postoperative Cobb angle that was proposed by Cheung et $a l^{(4)}$ could only have been used if a correlation had been found in our study between the same variable used by these authors. Thus, the correlation analysis was done by means of Pearson's correlation coefficient between

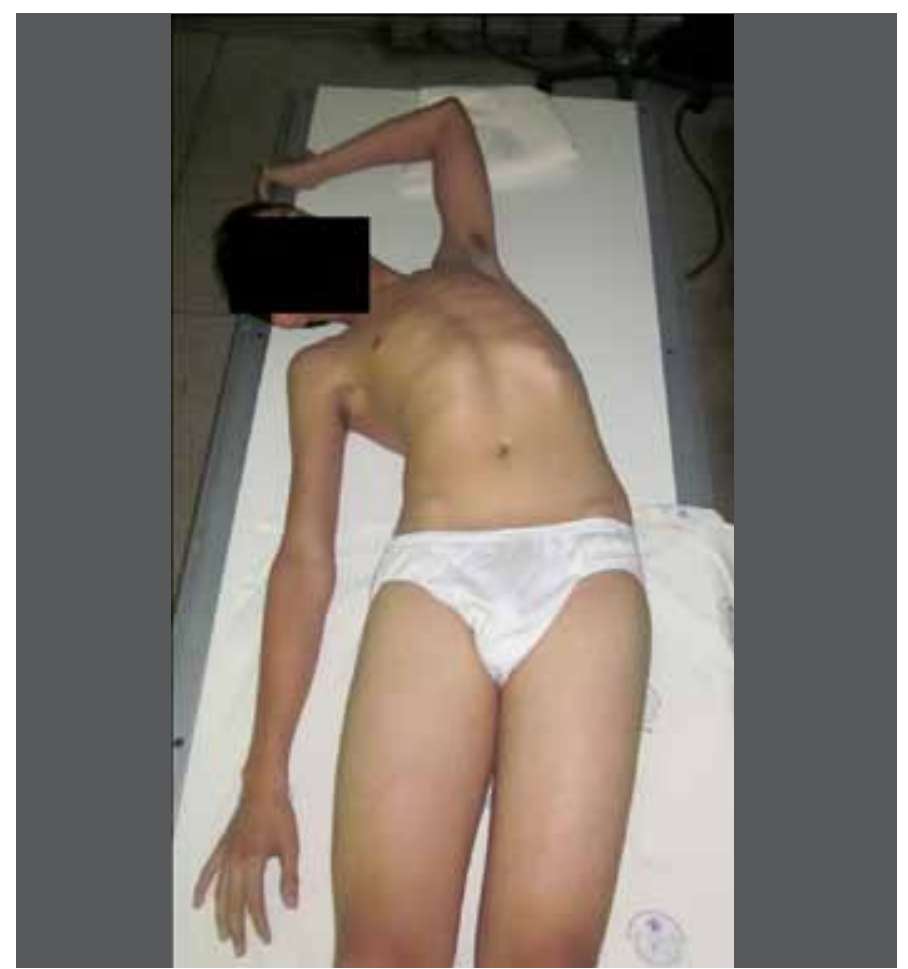

Figure 2 - Photographic image showing how lateral oblique radiographs were produced.

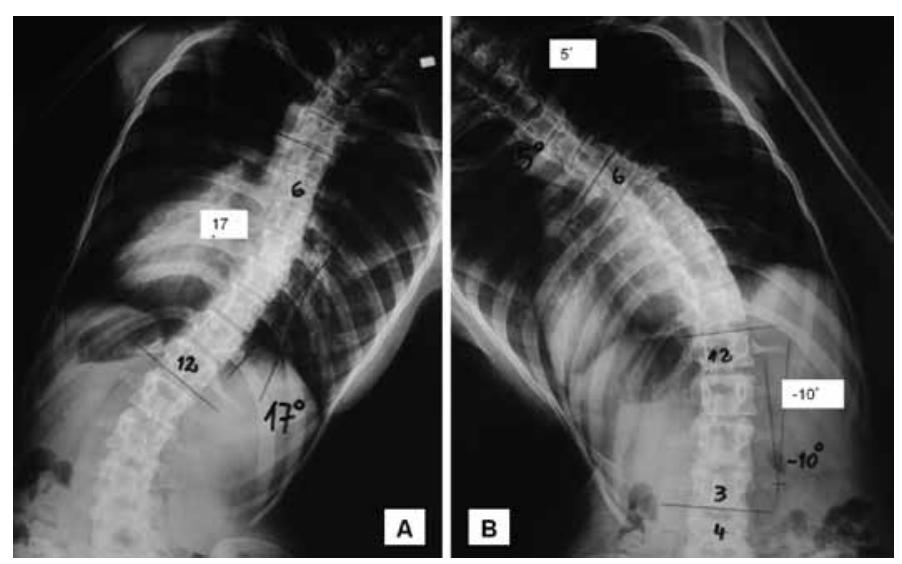

Figure 3 - Representative radiographic images of the study sample. A) Lateral oblique radiograph of main thoracic curve. B) Lateral oblique radiograph of lumbar curve.
FR $=\underline{\text { Preoperative Cobb angle }- \text { Cobb angle of lateral inclination }} \times 100 \%$ Preoperative Cobb angle

SCR $=\underline{\text { Preoperative Cobb angle }- \text { Postoperative Cobb angle }} \times 100 \%$ Preoperative Cobb angle

Figure 4 - Equations for obtaining the flexibility rate (FR) and surgical correction rate (SCR).

the postoperative Cobb angle and: the patient's age, the preoperative Cobb angle, the Cobb angles for the lateral inclinations and the flexibility rate.

The significance level was taken to be $5 \%$ for all the statistical analyses.

\section{RESULTS}

The radiographic description of the mean values for the pre and postoperative Cobb angles of the main thoracic curve and the preoperative lateral inclinations are presented in Table 1.

In this, it can be seen that there was a mean reduction from the preoperative Cobb to the postoperative Cobb of $46^{\circ}$, with $6^{\circ}$ of standard deviation.

The mean values for the flexibility rate and correction rate are presented in Table 2.

It was found that all the correlations for the main thoracic curve (in relation to the age, preoperative Cobb angle, Cobb angle of lateral inclination and flexibility rate) were statistically significant $(\mathrm{p}<$ 0.05), as shown in Table 3.

The fact that all these correlations for the main thoracic curve were statistically significant allowed us to use the equation proposed by Cheung et al ${ }^{(4)}$ to predict postoperative Cobb angles in our sample (Figure 5).

After obtaining the results from applying the equation, an analysis was done on the difference between the predicted result and the real result found for the postoperative Cobb angles (by means of the paired $\mathrm{t}$ test, with a significance level of $5 \%$ ), in order to obtain confirmation of the prediction power of this equation (Box 1).

As can be seen in Box 1, there was no statistically significant difference between the predicted and real values for the postoperative Cobb angle of the main thoracic curve $(p=0.389)$, through applying the equation to our sample. 
Table 1 - Characterization of the curves according to Cobb angles of the main thoracic curve.

\begin{tabular}{c|c|c|c}
\hline & Mean & DP & $\begin{array}{c}\text { 95\% confidence } \\
\text { interval }\end{array}$ \\
\hline $\begin{array}{c}\text { Preoperative Cobb } \\
\text { angle (ㅇ) }\end{array}$ & 55 & 6 & $52-58$ \\
\hline $\begin{array}{c}\text { Postoperative Cobb } \\
\text { angle (ㅇ) }\end{array}$ & 12 & 6 & $9-15$ \\
\hline Lateral inclination (ํ) & 26 & 12 & $20-30$ \\
\hline
\end{tabular}

Table 2 - Mean values, standard deviation and confidence interval of the flexibility rate and surgical correction rate.

\begin{tabular}{c|c|c|c}
\hline & Mean & DP & $\begin{array}{c}\text { 95\% confidence in- } \\
\text { terval }\end{array}$ \\
\hline Flexibility rate (\%) & $54^{*}$ & 18 & $48-63$ \\
\hline Correction rate (\%) & 79 & 10 & $74-83$ \\
\hline
\end{tabular}

Table 3 - Results from Pearson's correlation coefficient.

\begin{tabular}{c|c|c}
\hline & $\mathbf{R}$ & $\mathbf{p}$ \\
\hline $\begin{array}{c}\text { Postoperative main } \\
\text { thoracic Cobb angle }\end{array}$ & 0.52 & \\
\hline Age & 0.51 & $0.018^{*}$ \\
\hline $\begin{array}{c}\text { Preoperative } \\
\text { Cobb angle }\end{array}$ & 0.71 & $0.021^{*}$ \\
\hline $\begin{array}{c}\text { Cobb angle of lateral } \\
\text { inclination }\end{array}$ & -0.65 & $0.000^{*}$ \\
\hline IF & & $0.002^{*}$ \\
\hline $\begin{array}{c}\text { *Statistically signifi- } \\
\text { cant correlations at } p \\
<0.05 .\end{array}$ & & \\
\hline
\end{tabular}

Postoperative Cobb angle $=0.012+1.75 \times$ Age $-0.212 \times$ IF

Figure 5 - Equation for predicting the postoperative Cobb angle, proposed by Cheung et al ${ }^{(4)}$

\section{DISCUSSION}

Evaluation of the flexibility of all scoliotic curves (proximal thoracic, main thoracic and lumbar) forms part of the basic protocol for treating vertebral deformities $^{(7)}$. Different radiographic methods have been described for this purpose, such as use of active lateral oblique views ${ }^{(7-10)}$, views under traction in dorsal decubitus ${ }^{(6,11)}$ and views with a fulcrum at the apex of the deformity, in lateral decubitus ${ }^{(4,12)}$, among
Box 1 - Comparison between predicted and real postoperative Cobb angles of the main thoracic curve.

\begin{tabular}{|c|c|c|}
\hline & $\begin{array}{l}\text { Predicted postoperative } \\
\text { Cobb angle }{ }^{\star}\end{array}$ & $\begin{array}{l}\text { Real postoperative } \\
\text { Cobb angle* }\end{array}$ \\
\hline 1 & 19 & 20 \\
\hline 2 & 5 & 5 \\
\hline 3 & 5 & 9 \\
\hline 4 & 11 & 10 \\
\hline 5 & 11 & 8 \\
\hline 6 & 9 & 10 \\
\hline 7 & 8 & 3 \\
\hline 8 & 14 & 11 \\
\hline 9 & 17 & 13 \\
\hline 10 & 7 & 15 \\
\hline 11 & 4 & 6 \\
\hline 12 & 14 & 11 \\
\hline 13 & 14 & 14 \\
\hline 14 & 15 & 8 \\
\hline 15 & 9 & 1 \\
\hline 16 & 20 & 21 \\
\hline 17 & 20 & 14 \\
\hline 18 & 21 & 22 \\
\hline 19 & 16 & 20 \\
\hline 20 & 18 & 20 \\
\hline Mean & 13 & 12 \\
\hline
\end{tabular}

others. The basic concept is that the compensatory curves tend to become corrected spontaneously and thus should not be subjected routinely to arthrodesis ${ }^{(2)}$. In our service, we use radiographs with an active lateral oblique view in dorsal decubitus, because these are easy to perform and inexpensive.

Cheung et $a l^{(4)}$ were able to produce an equation for predicting the postoperative value of the main thoracic scoliotic curve, and this may assist in choosing the best operative technique, according to the stiffness of the curve. This may be very valuable, especially in cases in which selective thoracic arthrodesis is indicated, since there is a risk of iatrogenic decompensation of the lumbar curve. The results from the present study showed that there was no statistically significant difference between the value predicted by the equation and the real postoperative value, thus confirming the validity of using the predictive equation proposed by Cheung et $a l^{(4)}$ among Brazilian adolescents.

Exclusive use of pedicle screws in the thoracic spine for surgical treatment of AIS gained popularity following publication of the paper by Suk et $a l^{(3)}$ 
and today it is considered to be the gold standard for surgical correction of AIS ${ }^{(14)}$. These implants provide support in the three parts of the spine ${ }^{(15)}$ and have biomechanical characteristics that are superior to those of other types of materials such as hooks and sublaminar wires ${ }^{(16-18)}$. The main issue relating to pedicle screws is perhaps whether the greater angular correction of the deformities would result in better clinical and functional results. Some authors have demonstrated a positive correlation is this regard, measured through questionnaires standardized by the Scoliosis Research Society ${ }^{(19,20)}$. Because we believe that superior results are achieved through using assemblies consisting only of pedicle screws, as well as the safety of this method at thoracic levels ${ }^{(3,4,6)}$, we use this type of instrumentation preferentially in our service.

Furthermore, in relation to the operative correction rate, we found values that were very close to those described in other studies, such as Cheung et $a l^{(4)}$. It is noteworthy that these authors used assemblies with pedicle screws in all the vertebrae of the curve that underwent arthrodesis and, consequently, a greater number of anchorage points. In our sample, we used the philosophy of the method popularized by Cotrel and Dubousset ${ }^{(13)}$, which consists of instrumentation

\section{REFERENCES}

1. Cobb JR. Outline for the study of scoliosis. Instr Course Lect. 1948; 5:261-75.

2. Moe JH, Byrd JA. Idiopathic scoliosis. In: Lonsteins JE, Winter RB, Bradford DS RB, Olgivie JW, editors. Moe's textbook of scoliosis and other spinal deformities. 2nd ed. Philadelphia: Saunders; 1987. p.191-232.

3. Suk SI, Lee CK, Kim WJ, Chung YJ, Park YB. Segmental pedicle screw fixation in the treatment of thoracic idiopathic scoliosis. Spine (Phila Pa 1976). 1995;20(12):1399-405

4. Cheung WY, Lenke LG, Luk KD. Prediction of scoliosis correction with thoracic segmental pedicle screw constructs using fulcrum bending radiographs. Spine (Phila Pa 1976). 2010;35(5):557-61.

5. Hamzaoglu A, Talu U, Tezer M, Mirzanli C, Domanic U, Goksan SB. Assessment of curve flexibility in adolescent idiopathic scoliosis. Spine (Phila Pa 1976). 2005;30(14):1637-42.

6. Watanabe K, Kawakami N, Nishiwaki Y, Goto M, Tsuji T, Obara T, et al. Traction versus supine side-bending radiographs in determining flexibility: what factors influence these techniques? Spine (Phila Pa 1976). 2007;32(23):2604-9.

7. Lenke LG, Betz RR, Harms J, Bridwell KH, Clements DH, Lowe TG, et al. Adolescent idiopathic scoliosis: a new classification to determine extent of spinal arthrodesis. J Bone Joint Surg Am. 2001;83-A(8):1169-81.

8. Large DF, Doig WG, Dickens DR, Torode IP, Cole WG. Surgical treatment of double major scoliosis. Improvement of the lumbar curve after fusion of the thoracic curve. J Bone Joint Surg Br. 1991;73(1):121-4.

9. McCall RE, Bronson W. Criteria for selective fusion in idiopathic scoliosis using Cotrel-Dubousset instrumentation. J Pediatr Orthop. 1992;12(4):475-9.

10. Vaughan JJ, Winter RB, Lonstein JE. Comparison of the use of supine bending and traction radiographs in the selection of the fusion area in adolescent idiopathic scoliosis. Spine (Phila Pa 1976). 1996;21(21):2469-73. of some vertebrae that are considered to be strategic, while leaving others free from any type of implant. Despite not being an objective of the present study, this allows us to suggest the hypothesis that, for this type of population, greater density of screws seems not to increase the corrective power. This matter seems to us to be fundamental and deserves to be evaluated in a more specific manner, through randomized prospective studies in order to confirm this hypothesis.

Assessing whether the correction obtained through the operation was maintained over the years, or whether it was lost, was not an objective of our study. Thus, we only used the angular values from the immediate postoperative period. Other authors ${ }^{(4,18)}$ have reported that the mean loss of correction was minimal with exclusive use of pedicle screws, after two years of follow-up. Future analyses with this aim might answer this question in relation to our sample.

\section{CONCLUSION}

Through radiographs using a lateral oblique view obtained in the supine position, it is possible to predict the percentage operative correction achievable for the main thoracic curve, through using pedicle screws, in patients with AIS of Lenke types 1A and 1B.

11. Polly DW Jr, Sturm PF. Traction versus supine side bending. Which technique best determines curve flexibility? Spine (Phila Pa 1976). 1998;23(7):804-8.

12. Cheung KM, Luk KD. Prediction of correction of scoliosis with use of the fulcrum bending radiograph. J Bone Joint Surg Am. 1997;79(8):1144-50.

13. Cotrel $Y$, Dubousset J. [A new technic for segmental spinal osteosynthesis using the posterior approach]. Rev Chir Orthop Reparatrice Appar Mot. 1984;70(6):489-94

14. Lehman RA Jr, Lenke LG, Keeler KA, Kim YJ, Buchowski JM, Cheh G, et al. Operative treatment of adolescent idiopathic scoliosis with posterior pedicle screw-only constructs: minimum three-year follow-up of one hundred fourteen cases. Spine (Phila Pa 1976). 2008;33(14):1598-604.

15. Denis F. Spinal instability as defined by the three-column spine concept in acute spinal trauma. Clin Orthop Relat Res. 1984;(189):65-76.

16. Cheng I, Hay D, lezza A, Lindsey D, Lenke LG. Biomechanical analysis of derotation of the thoracic spine using pedicle screws. Spine (Phila Pa 1976). 2010;35(10):1039-43.

17. Suk SI, Lee CK, Min HJ, Cho KH, Oh JH. Comparison of Cotrel-Dubousset pedicle screws and hooks in the treatment of idiopathic scoliosis. Int Orthop. 1994;18(6):341-6.

18. Dobbs MB, Lenke LG, Kim YJ, Kamath G, Peelle MW, Bridwell KH. Selective posterior thoracic fusions for adolescent idiopathic scoliosis: comparison of hooks versus pedicle screws. Spine (Phila Pa 1976). 2006;31(20):2400-4.

19. Haher TR, Merola A, Zipnick RI, Gorup J, Mannor D, Orchowski J. Meta-analysis of surgical outcome in adolescent idiopathic scoliosis. A 35-year English literature review of 11,000 patients. Spine (Phila Pa 1976). 1995;20(14):1575-84.

20. Avanzi O, Landim E, Meves R, Caffaro MFS, Umeta RSG. Escoliose idiopática do adolescente: correlação entre parâmetros radiográficos de correção e resultado clínico de tratamento. Coluna/Columna. 2008;7(3)201-8 